\title{
Measure Twice, Estimate Once: Pacific Salmon Population Viability Analysis for Highly Variable Populations
}

\author{
Charles M. Paulsen* \\ 16016 Southwest Boones Ferry Road, Suite 4, Lake Oswego, Oregon 97035, USA
}

RichARD A. HINRICHSEN

Hinrichsen Environmental Services, 4608 Union Bay Place NE, Seattle, Washington 98105-4027, USA

TIMOTHY R. FISHER

Fisher Fisheries, Ltd. 18403 South Clear Acres Drive, Oregon City, Oregon 97045, USA

\begin{abstract}
Because many stocks of Pacific salmon Oncorhynchus spp. are listed under the U.S. Endangered Species Act (ESA), research has focused on predicting the future population dynamics for these low-abundance stocks. One method used to make predictions is known as population viability analysis. Pacific salmon populations exhibit much higher apparent variability than other ESA-listed vertebrates, and high variability increases the probability of extinction. If the high variability is primarily due to counting methods, it could be reduced in model predictions by using methods that correct for measurement error, sampling error, or both. Using data from British Columbia pink salmon O. gorbuscha and Snake River springor summer-run Chinook salmon O. tshawytscha and several modeling approaches (Ricker, Dennis, and statespace models), we compared repeated counts of the same population (e.g., spawner and fry, dam and redd counts). We applied the methods to the first half of the time series and compared the predictions with the last half of the time series. The results demonstrated that having counts of all life stages of a Pacific salmon population is no guarantee that variability will be markedly reduced. Measurement error is not the primary cause of high variability in empirical estimates of abundance or in predicted future abundance for the stocks analyzed. The very wide bounds on predicted abundance limit the utility of the model predictions for making management decisions. Furthermore, obtaining more accurate or complete measurements of population abundance is unlikely to reduce the wide error bounds in predictions of future abundances.
\end{abstract}

Over the past 15 years many stocks of Pacific salmon Oncorhynchus spp. have been listed as threatened or endangered under the U.S. Endangered Species Act (ESA) (NOAA Fisheries 2005). This has focused researchers' attention on a difficult problem: how best to predict the future course of population dynamics for listed stocks whose abundances are often greatly reduced from historic levels. One method used to make such predictions is known as population viability analysis (PVA). Several PVA methods have been used for modeling listed salmon populations, beginning with spawner-recruit (SR) models familiar to many fisheries biologists (e.g., Marmorek et al. 1998; Paulsen and Hinrichsen 2002). More recently, researchers, drawing on methods used for other ESAlisted vertebrate species (e.g., northern spotted owl Strix occidentalis caurina, loggerhead sea turtle $\mathrm{Ca}$ retta caretta, snail kite Rostrhamus sociabilis, and

\footnotetext{
* Corresponding author:

cpaulsen@paulsenenvironmentalresearch.com
}

Received November 28, 2005; accepted October 27, 2006 Published online March 12, 2007
Bachman's sparrow Aimophifa aestivulis; Morris et al. 2002), have employed diffusion approximation methods (e.g., Holmes 2004; Holmes and Semmens 2004). These methods have also been applied for long-term projections by management agencies at the evolutionarily significant unit (ESU) and population levels (NOAA 2000). Unlike spawner-recruit models diffusion approximation methods do not require information on the age of returning progeny (recruits) and, therefore, can be employed for stocks where the ageat-return data may be incomplete or missing. In the terminology of Dunham et al. (2006), the spawnerrecruit methods are "matrix" models, while the simpler diffusion approximations are "scalar" methods. Matrix models may yield more accurate results in some circumstances at the cost of requiring data on age structure. The details differ among models, but in all cases one purpose for applying them is to predict future population numbers (including the likelihood of extinction) based on past trends in abundance.

In comparing diffusion approximation analyses for ESA-listed Pacific salmon with those for other species, researchers have noted that the Pacific salmon 
populations exhibit much higher apparent variability than other listed vertebrates (Hinrichsen 2001). This is crucial to the predictions arising from PVA since, all else being equal, high variability increases the probability of extinction, sometimes substantially. This occurs because modeled population trajectories can reach zero (i.e., become extinct), or fall below a quasiextinction threshold, simply at random. Because this high variability appears to be unique to Pacific salmon populations (when compared with other ESA-listed vertebrates), much effort has recently been expended exploring methods to help understand and correct for high population variability (e.g., Holmes 2001; Staples et al. 2004). If the apparent high variability is primarily a problem with counting methods it could be reduced by correcting for measurement error, sampling error, or both, and other possible problems. Some researchers have questioned whether PVA methods are useful or meaningful (Ludwig 1999; Fieberg and Ellner 2000). However, no researcher to our knowledge has taken an empirical approach to this problem for Pacific salmon populations; i.e., comparing modeled population projections with empirical data on population abundance.

Because Pacific salmon have been culturally and economically important species to European settlers for over 100 years, substantial resources have been expended to estimate annual subadult and adult harvest, returns of adult spawners, and, less frequently, the number of emigrating juveniles (e.g., Marmorek and Peters 1998; Petrosky et al. 2001). While no counting method is entirely free of error methods commonly employed include relatively accurate weir or dam counts for many stocks (as opposed to counts of parr or smolts or harvest estimates). In a few cases repeated estimates of abundance are made for the same stock and life stage (e.g., counts at multiple dams and repeated spawning ground surveys). In this study, we take advantage of several of these repeated estimates of abundance to investigate whether high variability in Pacific salmon population abundance can be at least partially attributed to measurement error. If the variability is a consequence of measurement error, then better methods might be employed to count salmon, albeit at higher costs than at present. This, in turn, will reduce uncertainty and inaccuracies in the population predictions resulting from PVAs. If, on the other hand, measurement error is a small fraction of the overall variability, this will have important implications for predicted population dynamics for ESA-listed stocks of Pacific salmon. This occurs because high variability leads to high risk of extinction. Furthermore, high variability limits researchers' abilities to provide useful predictions of future population trajectories to fishery management and regulatory agencies.
We begin with some definitions of sampling and measurement error. We then present the data used in the analyses, giving particular attention to the accuracy of estimates of adult and redd (nest) abundance. Next, we outline the methods applied to the data to compare repeated counts of the same population (e.g., dam and redd counts), along with the PVA methods employed to correct for sampling and measurement error. We then estimate model parameters using the first 20 years of the data series data and compare the predictions with the last 18-24 years of empirical estimates. We conclude with a discussion of the implications of high variability for predicting the future population dynamics of listed stocks using PVA.

\section{Methods}

Measurement error.-Measurement error may occur in several forms, some of which are easier to correct (via improved counting methods) than others. The first and most obvious is simple miscounting (e.g., 10 redds are present in a spawning reach, but observers only locate 9 of them due to high turbidity). The second is that only part of the spawning population may be counted (sampling error), as is often the case for index population or index reach counts. Here, the problem is that some adults are spawning outside the index reach and the index reach contains a variable fraction of the total spawning population over spawning cycles. Both problems can be addressed by counting adult spawners at a weir below the spawning area or employing repeated redd counts over the entire spawning area. The third potential problem is that even complete counts of adult spawners do not enumerate the entire population (another case of sampling error): juvenile and adult fish at sea are obviously not counted at dams or weirs or during spawning surveys. For most Pacific salmon species, this problem does not admit to any straightforward solution.

Data.-We used several time series of adult spawning escapements and redd counts and one series of juvenile production to test the predictive capabilities of the SR and PVA models; we present these data in increasing order of their susceptibility to measurement error. The first is a series of adult spawning escapements for pink salmon $O$. gorbuscha and the resulting production of juveniles, which we used to investigate whether the apparent high variability of Pacific salmon populations is caused by measuring only one life stage (spawners) among several that are possible (e.g., fry, parr, smolts, subadults, and adults). The series is taken from Essington et al. (2000) and consists of weir counts of female pink salmon and the resulting fry production in Weaver Creek, British Columbia from 1965 to 1997 (Figure 1). Because all 


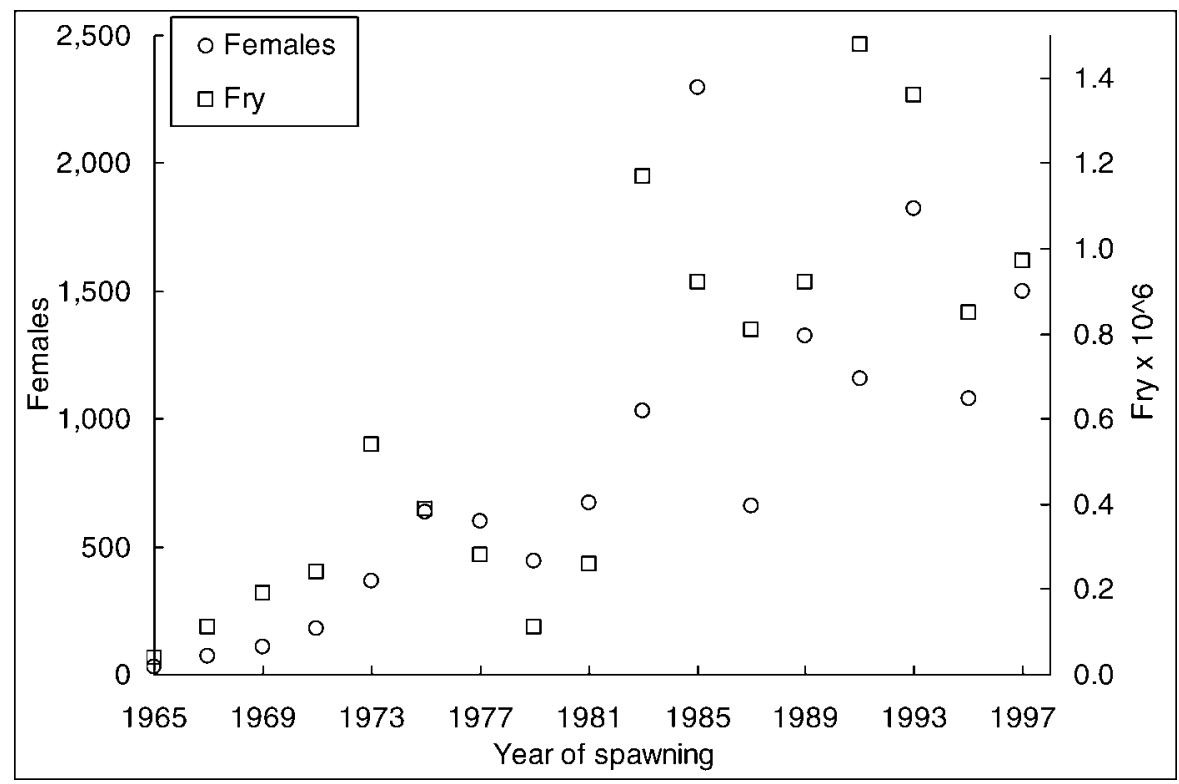

FIGURE 1.-Weaver Creek pink salmon spawning females and fry produced (from data in Essington et al. 2000).

pink salmon spawning populations consist of a single age-class, the estimates of spawning females and fry constitute a near census of the population, even though spawning males are omitted from the counts.

The second time series consisted of counts of wildorigin spring-summer-run Chinook salmon $O$. tshawytscha listed as threatened under the ESA in 1992. Adults passing upstream were counted as they pass over Ice Harbor (ICH), Lower Monumental, Little Goose, and Lower Granite (LGR) dams on the Snake River on their spawning migration to the tributary subbasins of the lower Snake River basin (Figure 2; Appendix 1). Details on data sources and counting methods for these estimates are outlined in Appendix 2. Since ICH was constructed in 1962 there has been an almost continuous record of spring-summer-run Chinook salmon that ascended the fish ladders at each dam (Figure 3). Returning adults (ages 4 and 5) are separated from jacks (age 3) based on fish length as they are observed passing the fish counting window in each ladder. Some fish may not be counted due to passage via navigation locks, and others fall back below the dam, passing downstream via the turbines, spillways, or locks. However, the dam counts are believed to represent a near census of the population of adults returning to the Snake River basin above LGR. Since the late 1960s numerous spring-summer-run Chinook salmon hatchery programs have been established in the Snake River basin above LGR (Matthews and Waples 1991; Waples et al. 1991). However, dam counts are maintained separately for both wild- and hatchery-origin Chinook salmon based on the presence of a complete adipose fin. (Virtually all hatchery-origin juveniles have their adipose fin clipped before release.) The wild proportion of the escapement was estimated by subtracting tributary harvest of hatchery adults and total hatchery returns of adults from the combined wild- and hatchery-origin dam count (Figure 4).

The third time series consisted of counts of redds for spring-summer-run Chinook salmon in the lower Snake River basin above LGR except for the Clearwater River basin, which was excluded from the ESAlisted population because the origin of the run is uncertain (Figure 4; Appendix 1). We used redds from a combination of ground and aerial counts in reaches that were counted consistently in each stream known to support spring-summer-run Chinook salmon spawning populations. Redd density (redds per kilometer) for the run-at-large is an aggregate of redds counted in 34 spawning areas (Figure 2). Details on data sources and counting methods for these estimates are outlined in Appendix 2.

The final time series consisted of recruits (adult progeny returning to the uppermost dam or the spawning grounds) produced from both adults at the uppermost dam and seven Snake River springsummer-run Chinook salmon index stocks (Figure 2). The methods are reviewed in Schaller et al. (1999), and the source data for individual stocks and years are found in Beamesderfer et al. (1996). More details on 


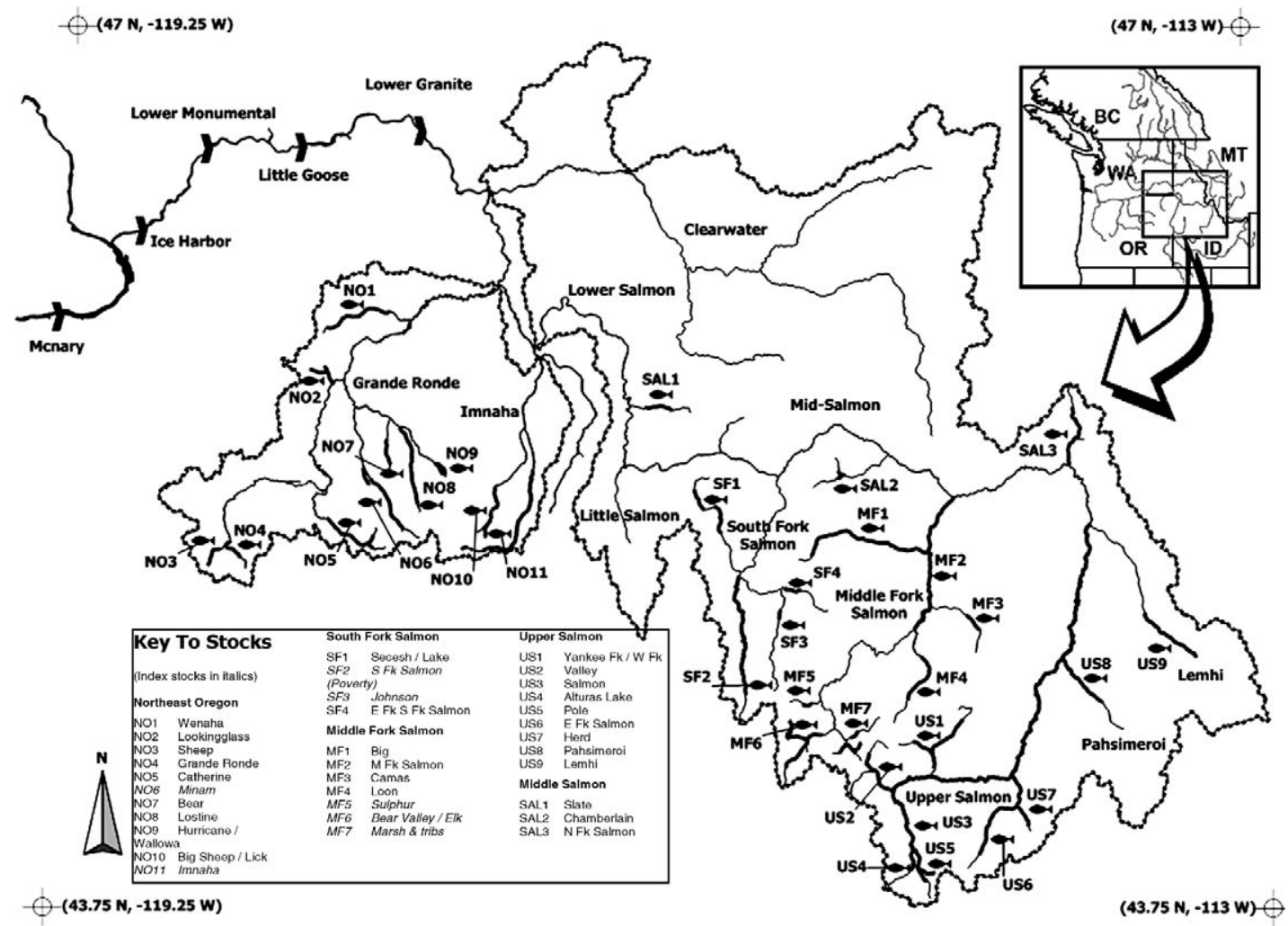

FIGURE 2.-Map of the study area showing the watershed accessible to Pacific salmon above Lower Granite Dam (dotted line), major rivers (solid lines), main-stem dams ("V" symbols), stocks used for redd densities (fish symbols), and major spawning areas (heavy lines).

the data sources and methods used for these estimates are outlined in Appendix 2.

As one moves from dam counts to redd densities to run reconstructions, more data and more assumptions are required. Furthermore, there is greater potential for measurement error when one must separate hatchery from wild fish at the dams, allow for the fact that redd counts cover index areas only, and extrapolate age at return (estimated from limited samples) to entire stocks.

Spawner-recruit model.-We first considered a Ricker model (Ricker 1954), which makes use of age-structured spawner data to construct a time series of recruits (progeny returning to spawn in the future) versus spawners. The Ricker model is of the form

$$
R_{t}=S_{t} \exp \left(a-b S_{t}+w_{t}\right)
$$

where $R_{t}$ is recruits from the spawners in brood year $t$, $S_{t}$ is spawners in year $t$, and $w_{t}$ is uncorrelated errors with mean zero and constant variance $\sigma^{2}$. Age-at-return estimates are required to attribute recruits to the spawning population that produced them (e.g., 4- year-old recruits are the progeny of spawners from 4 years ago). We fitted this model in the usual way by applying ordinary least squares regression, that is,

$$
\log _{e}\left(R_{t} / S_{t}\right)=a-b S_{t}+w_{t},
$$

where $t=1,2, \ldots, T$ represents brood year (19621981). The residuals are a mixture of measurement error and process or environmental variation. In contrast to the models we consider next, this model is density dependent, so the spawning population declines as recruits per spawner increase.

All three models may also be estimated by means of bootstrapping or other methods that incorporate parameter uncertainty (Ellner and Fieberg 2003). Briefly, the bootstrapping consists of drawing repeatedly from the data (with replacement), estimating a set of parameters including the error term, and using the resulting parameter set to project future population numbers. This incorporates both parameter uncertainty and prediction uncertainty. For the populations analyzed here, these methods result in only a slight 


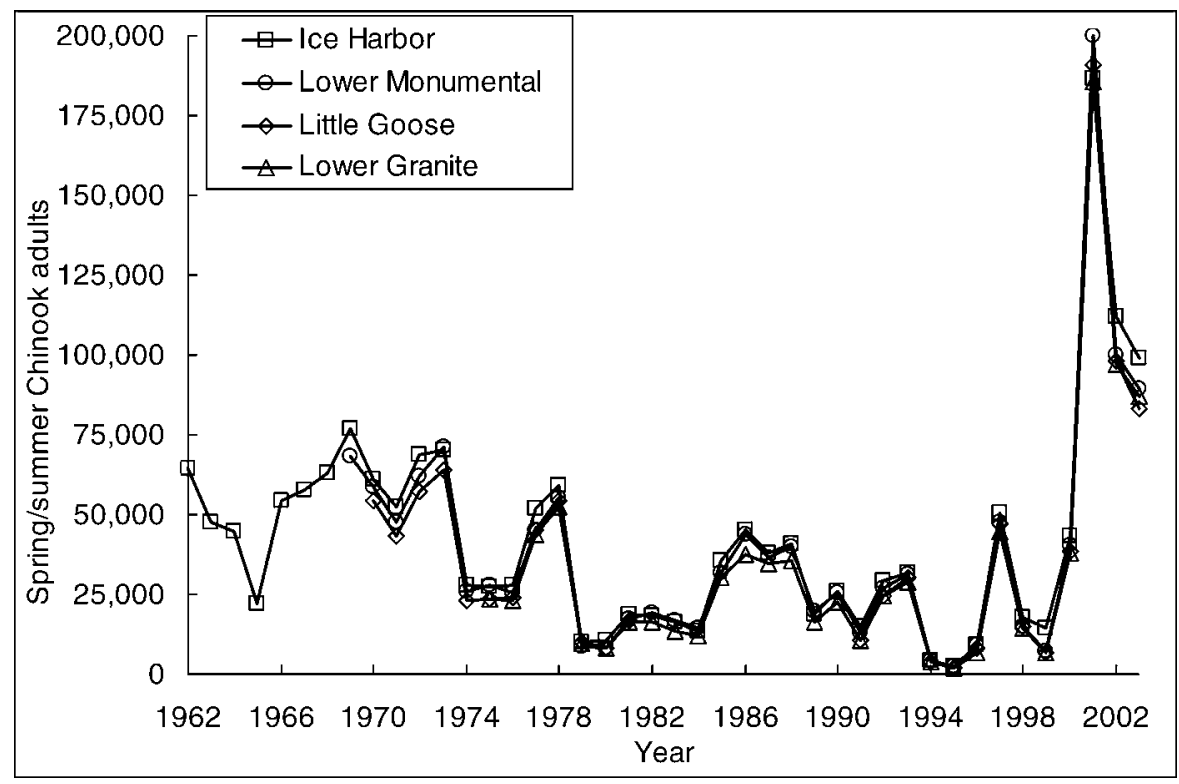

FIGURE 3.-Counts of total (hatchery and wild) spring-summer-run Chinook salmon adults passing the four main-stem Snake River dams from the most downstream (Ice Harbor) to the most upstream (Lower Granite).

increase in the prediction intervals and so are not reported.

Dennis model.-The Dennis model is density independent and does not make use of age-at-return data. Instead of modeling recruits per spawner as the
Ricker model does, it models spawners in a given year in terms of spawners from the previous year. The model was developed by Dennis et al. (1991) and is a stochastic, discrete-time model of exponential growth described by the equation

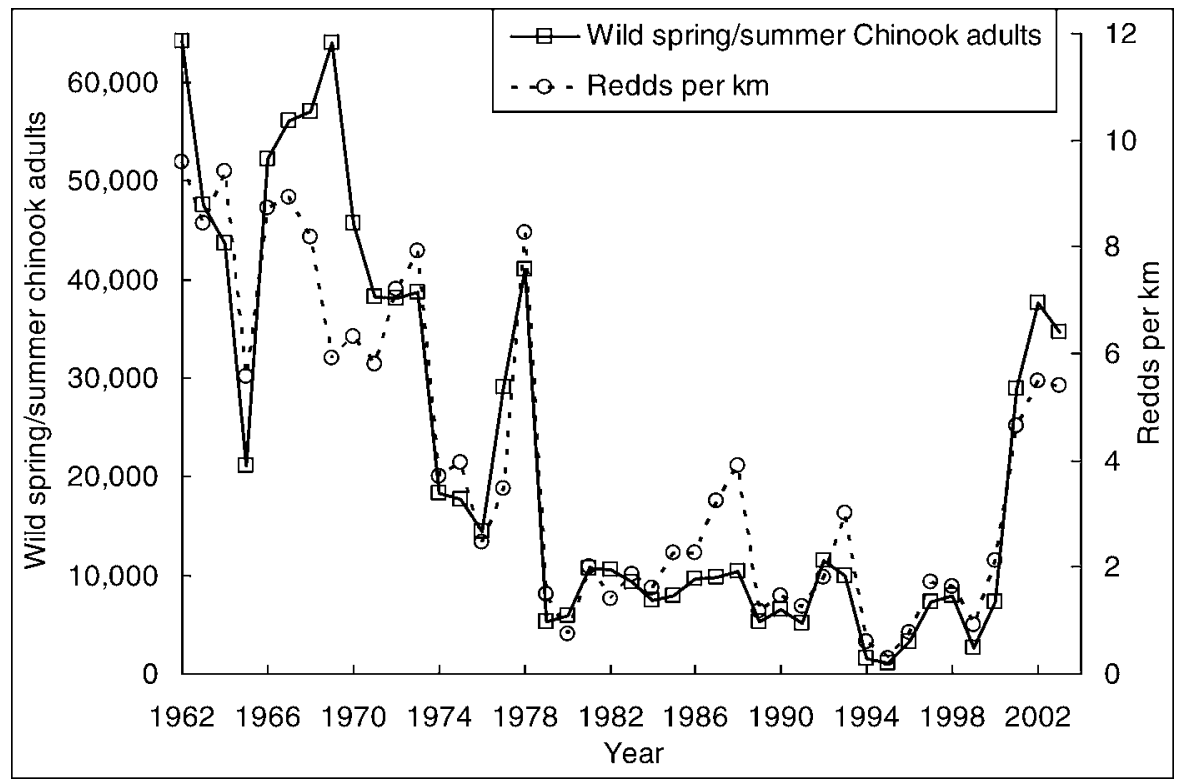

FIGURE 4.-Estimated wild spring-summer-run Chinook salmon adults that passed the uppermost Snake River dam and redds per river kilometer above Lower Granite Dam (excluding the Clearwater basin). 
TABLE 1.-Descriptions of the three population viability analysis models used in the analyses of Pacific salmon.

\begin{tabular}{llll}
\hline & \multicolumn{1}{c}{ Method } & \multicolumn{1}{c}{ State-space } \\
\cline { 2 - 4 } \multicolumn{1}{c}{ Feature } & \multicolumn{1}{c}{ Ricker } & \multicolumn{1}{c}{ Dennis } & No \\
\hline Age data required & Yes & No & Restricted maximum likelihood \\
Estimation method & Ordinary least squares & Ordinary least squares & Yes \\
Accounts for errors in population estimates & Not directly & No & Less so \\
Widely used in past & Yes (for Pacific salmon) & Yes (for other vertebrate species) & Low \\
Ease of interpretation & High & Medium & No \\
Use with missing data & Yes & Yes & Po \\
\hline
\end{tabular}

$$
S_{t}=S_{t-1} \exp \left(\mu+\eta_{t}\right)
$$

where $t=1,2, \ldots, T, S_{t}$ represents population abundance at time $t$, and $\mu$ is the deterministic per-unitabundance growth rate in population density. The error term, $\eta_{t}$, is included to model the stochastic deviations from long-term trend due to environmental effects. These errors are assumed to have a normal distribution with mean zero and variance $Q$. Letting $\alpha=\log _{e}\left(S_{t}\right)$, the growth process can be expressed as

$$
\alpha_{t}=\alpha_{t-1}+\mu+\eta_{t}
$$

which represents a discrete-time random walk with drift process.

State-space models.-Because Pacific salmon may be counted with errors of the sort previously described we also used a model incorporating measurement error. The observed log abundance, $y_{t}$, is related to the true "state" through the equation

$$
y_{t}=\alpha_{t}+\varepsilon_{t},
$$

where $\alpha_{t}=\log _{e}\left(S_{t}\right)$ is the true log abundance of spawners, and $\varepsilon_{t}$ represents uncorrelated measurement errors (differences between actual and observed or estimated spawners) with mean zero and variance $H$.

Estimates of the state-space model parameters are obtained by means of the restricted maximum likelihood (REML) method. Although the method is only briefly summarized here, the details may be found in Staples et al. (2004). The REML method uses the fact that the second differences of the observed escapements follow a multivariate normal distribution that does not depend on $\mu$ (since the $\mu$ terms in each $y$ cancel) and has a known covariance structure that depends on $Q$ (environmental or process error variance) and $H$ (measurement error variance). The likelihood function formed by this multivariate normal distribution is maximized to obtain the REML estimates of $Q$ and $H$. The parameter $\mu$ is then estimated using a generalized least squares estimator of trend. The REML method was implemented using the $\mathrm{R}$ statistical package, and the likelihood function was maximized using the Boyden, Fletcher, Goldfarb, and
Shanno quasi-Newton method with box constraints (LBFGS-B) of Byrd et al. (1995), which allowed $Q$ and $H$ to be constrained to be nonnegative (see Appendix 3 for $\mathrm{R}$ code to estimate the model).

Although the Ricker, Dennis, and state-space models are quite different, they all share an important feature: stationarity. That is, they all assume that the model parameters $(a, b, \mu$, etc.) are constant over time, showing no shifts due to anthropogenic effects or climate regime shifts. Furthermore, they assume that residuals are uncorrelated with one another. Therefore, abrupt jumps in spawner abundance are not likely to occur in projections or predictions made with these models. Table 1 summarizes model features and data requirements.

Population prediction.-To determine how well the alternative population models project spawner abundance, we compared predicted spawner abundance with actual population abundance over a time span of more than 20 years. Starting with the estimated spawner abundances in 1981 and the parameter estimates derived from the 1962-1981 data we predicted the spawner trajectories for 1982-2004 and compared the predictions with the actual spawner observations over the same period. We did this for the Ricker, Dennis, and state-space models.

To test the Ricker model, we constructed predicted trajectories using equation (2) prospectively. We began the projections by setting $S_{16}-S_{20}$ equal to the observed spawner abundances over 1977-1981, then used the Ricker equation to project spawner abundances over 1982-2004 $\left(S_{21}-S_{44}\right)$ where $S_{44}$ represented spawner abundance in 2004. The age structure (age at return) of the projected recruits was assumed to be constant over time and was set to the average observed age structure over 1962-1981. We constructed 10,000 spawner trajectories and used these to build envelopes that encompassed $90 \%$ of the predicted log spawner abundances (5th and 95th percentiles of the predicted distribution). To test how accurately the spawnerrecruit model predicted spawners, we determined whether the prediction envelopes contained the actual spawner abundance observations over 1982-2004. 
To use Dennis model for prediction, we set $\mu$ and $Q$ equal to their ordinary least squares estimates. Prediction was accomplished by the Dennis model (equation 4) prospectively. We began the projections by setting $\alpha_{20}$ equal to the observed log spawner abundance in 1981, then used equation (4) to project the future log spawner abundances $\alpha_{21}-\alpha_{44}$, where $\alpha_{44}$ represented the log spawner abundance in 2004. Using this projection technique, we constructed 10,000 trajectories and used these to build envelopes that encompassed $90 \%$ of the predicted spawner abundances.

To use the state-space model for prediction, we set the state-space parameters equal to their REML estimates. Prediction was accomplished by means of the state-space model (equation 5) prospectively. As with the Dennis model, we began the projections by setting $\alpha_{20}$ equal to the observed log spawner abundance in 1981, then used equation (5) to project the actual log spawner abundances $\alpha_{21}-\alpha_{44}$. In contrast to the Dennis projections these projected log abundances were then perturbed by the estimated measurement error distributions to arrive at predictions of observed log spawner abundances. Because the measurement errors are assumed to be independent of one another, their variation does not propagate in the predictions. Using this projection technique, we constructed 10,000 trajectories and used these to build envelopes that encompassed $90 \%$ of the predicted spawner abundances.

\section{Results}

Having counts of all life stages of a Pacific salmon population is no guarantee that variability will be markedly reduced (Figure 1). The counts of female pink salmon spawners in Weaver Creek vary from less than 100 to over 2,000 during the 17 generations for which data are available. Similarly, estimates of fry production vary by a factor of about 40 . The inability to count juveniles in freshwater or maturing fish at sea will reduce the accuracy of population size estimates, but having a census of an entire Pacific salmon population does not appear to reduce the interannual variation in population abundance.

Counts of adult spring-summer-run Chinook salmon at the lower Snake River dams (Figure 3) are both highly variable and highly correlated with each other (Spearman $r>0.988$ among the four dams). The very high correlation among the counts, combined with the fact that the dam counts are a near census of the population of mature adults (see Methods and Appendix 1) strongly suggests that the high variability in the counts is not a consequence of measurement error, but is instead a feature of the actual population dynamics of this stock. One consideration with these data is that processes that might produce measurement error (e.g., fallback of adults) could vary from year to year, but still be correlated across the four dams. Strong evidence exists from radio tagging studies that fallback over the dams and ladder reascension among springsummer-run Chinook salmon (leading to inflation of adult Chinook salmon counts at the Snake River dams) is minimal and correlated with river flow. This results in a modest (2-11\%) overcounting bias at the mainstem dams (Boggs et al. 2004). However, we found that correlation between dam counts at Lower Granite, which has a bias of no more than $2 \%$, with Ice Harbor, which has a maximum bias of $11 \%$, was extremely high (Spearman $r>0.992$ ).

There also appears to be high variability over time in the wild portion of the adult return to the dams and associated redd densities in the 34 spawning areas (Figure 4). In addition, the redd counts, estimated independently from the dam counts, are highly correlated with the wild adult spawner estimate at the uppermost dam (Spearman $r=0.946$ ). As one might expect, since the redd counts are an index of a subset of the adult spawning population, the correlation is not quite as strong as the correlations among the dam counts of adult spawners, but the correlation again suggests that the high variability in the abundance over time is a real phenomenon rather than an artifact of measurement error.

The results from the application of the three models (Ricker, Dennis, and state-space) to the estimates of wild adults at the uppermost dam and the seven index stocks are shown in Table 2. The stochastic growth rate, $\mu$, for both the Dennis model and the state-space model are negative for all eight populations, indicating declining numbers of adult spawners for the 20-year period. Similarly, the Ricker $a$ parameter is negative for all populations, suggesting that, on average, the stocks did not replace themselves. The state-space model is the only model that attempts to estimate both environmental variation $(Q)$ and measurement error $(H)$. In all eight cases measurement error is estimated to be substantially higher than environmental variation. For the counts of adult spawners at the dams, commonly accepted to be the most accurate of the time series we used, the state-space model suggests that measurement error of 0.18 is three times higher than environmental variation, which is estimated at 0.0596 . The most extreme example of this is for the Poverty Flat index population where environmental variation is estimated to be zero with all the variation accounted for as measurement error (Table 2).

Figures 5-7 display model projections and actual abundance for an illustrative subset of the eight 
TABLE 2.-Estimated parameters for the three population viability analysis models with data from 1962 to 1981.

\begin{tabular}{|c|c|c|c|c|c|c|c|c|}
\hline \multirow[b]{3}{*}{ Population } & \multicolumn{8}{|c|}{ Model } \\
\hline & \multicolumn{3}{|c|}{ Ricker } & \multicolumn{2}{|c|}{ Dennis } & \multicolumn{3}{|c|}{ State-space } \\
\hline & $a$ & $b$ & $\sigma^{2}$ & $\mu$ & $\sigma^{2}$ & $\mu$ & $Q$ & $H$ \\
\hline $\begin{array}{l}\text { Wild adults at uppermost dam } \\
\text { Index stocks }\end{array}$ & -0.2146 & $-4.48 \times 10^{-6}$ & 0.6631 & -0.094 & 0.4009 & -0.099 & 0.0596 & 0.1845 \\
\hline Minam & 0.5211 & -0.0019 & 0.9977 & -0.143 & 0.634 & -0.137 & 0.0919 & 0.2387 \\
\hline Imnaha & 0.6168 & -0.0007 & 0.5767 & -0.048 & 0.5055 & -0.055 & 0.0853 & 0.2032 \\
\hline Poverty Flat & 0.0412 & -0.0006 & 0.5631 & -0.138 & 0.2441 & -0.148 & 0 & 0.1055 \\
\hline Johnson Creek & 0.1339 & -0.0014 & 0.7417 & -0.099 & 0.377 & -0.107 & 0.044 & 0.1621 \\
\hline Marsh Creek & -0.1915 & -0.0006 & 1.3802 & -0.077 & 0.8975 & -0.122 & 0.1 & 0.3914 \\
\hline Sulphur Creek & 0.0368 & -0.0015 & 2.1915 & -0.105 & 1.3107 & -0.125 & 0.2131 & 0.521 \\
\hline Bear Valley-Elk Creek & -0.4608 & -0.0001 & 0.8982 & -0.126 & 0.6208 & -0.148 & 0.0409 & 0.2753 \\
\hline
\end{tabular}

populations: wild fish at the uppermost dam, Bear Valley, and Sulfur Creek. The numerical model results have several consequences for the model predictions. The Ricker model underpredicts the 2003 returns of wild adult spawners at the uppermost dam, with lower and upper bounds of 1,400 and 24,000 wild adults (Figure 5a). The Dennis model predictions have a lower $5 \%$ bound of 11 adults by 2003 and an upper $95 \%$ bound of approximately 90,000 adults, which is about $50 \%$ more wild adults than have returned to the Snake River basin since ICH was completed in 1962 (Figure 5b). The state-space model, on the other hand, predicts a steady decline in wild adult spawners such that predicted returns for 2003 are between 150 and 9,000 adults, while actual returns were approximately 35,000 (Figure 5c).

Model results for the Bear Valley-Elk Creek springsummer-run Chinook salmon index population are broadly similar to those for wild adults at the uppermost dam. For the Ricker model (Figure 6a) the upper and lower bounds do bracket the actual values with the predicted upper bound always being below the maximum observed values from the early 1960s. The Dennis model (Figure $6 \mathrm{~b}$ ) predicts redd density of between 0 and $40 \mathrm{redds} / \mathrm{km}$, with the upper bound more than twice the observed maximum redd density of $18 \mathrm{redds} / \mathrm{km}$ in 1963. The state-space model again under-predicts observed redd density with the upper bound being too low by a factor of 10 (Figure 6c).

Application of the models to the Sulfur Creek spring-summer-run Chinook salmon index population shows the Ricker model's upper bounds are much higher than any observed values (Figure 7a). Very wide upper and lower bounds are apparent for the Dennis model (Figure $7 \mathrm{~b}$ ), the upper bound $(>1,000$ redds $/ \mathrm{km}$ ) being more than 30 times the maximum observed ( 28 redds $/ \mathrm{km}$ in 1966). The state-space model again underpredicts recent redd density (Figure $7 \mathrm{c}$ ).

\section{Discussion}

Measurement error, in both the commonsense use (e.g., five fish were counted when 10 were present) and in the more technical senses defined earlier, can be problematic for measuring Pacific salmon populations. However, the results suggest that it is not the primary cause of high variability in estimates of Pacific salmon population abundance. The result contradicts findings for other species where estimates of environmental variance are usually small compared with sampling error variance (Holmes 2001). This genuinely high variability, in turn, limits the utility of these types of models to predict the future. Furthermore, the results suggest that more accurate or complete measurements of population abundance are unlikely to reduce the variation in abundance estimates. High variation in abundance, in turn, results in very wide bounds on model predictions of future abundance.

Therefore, fishery managers should treat the predictions made by PVA models with caution. For the stocks analyzed here the predictions are either misleading (as with the state-space predictions for the wild spring-summer-run Chinook salmon adults at the uppermost dam) or are so broad as to be useless. For example, for the Sulfur Creek index population the Dennis model predicts that the stock will either decrease to zero or increase to levels many times higher than have ever been observed. At least on the face of it, one does not really need a model to make this conclusion. The state-space model often underpredicted returns, attributing what appears to be real (environmental) variation to measurement error. Furthermore, although the Ricker model, using additional data on age at return of adult spawners, performed somewhat better than the Dennis or state-space models, its predictions were also very broad. These results occurred despite our having used 20 years of data to calibrate the models-substantially more than is available for many ESA-listed stocks of Pacific salmon 


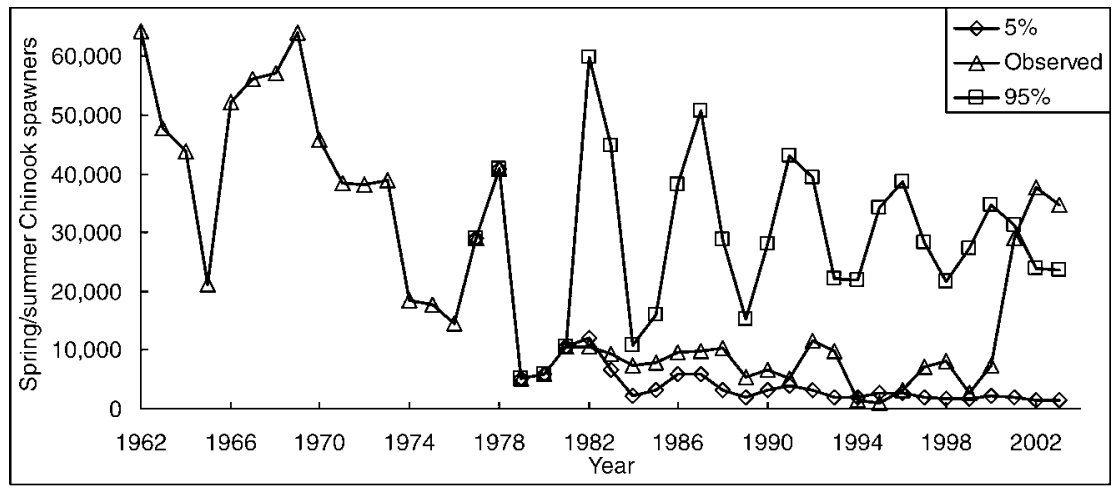

5a.-Ricker model

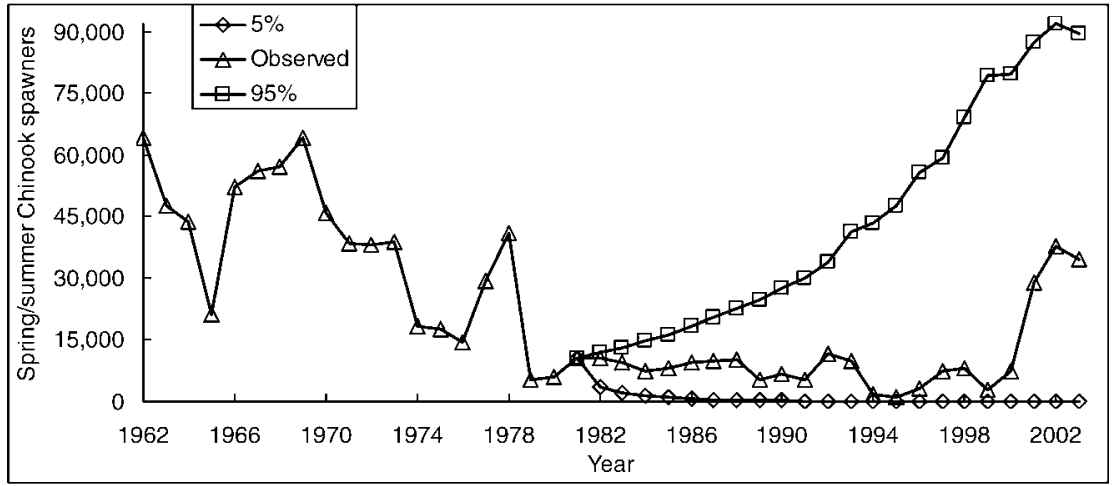

5b.-Dennis model

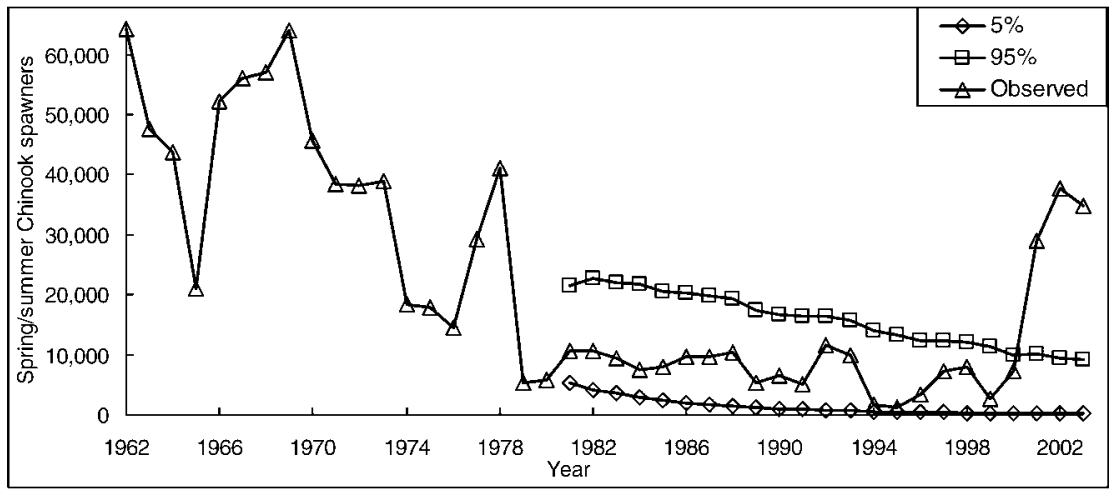

5c.-State-space model

FIGURE 5.-Number of wild spring-summer-run Chinook salmon spawners that passed the uppermost Snake River dam, as estimated by the (a) Ricker, (b) Dennis, and (c) state-space models. The lines represent the observed values and the 5th and 95th percentiles of the model estimates. 


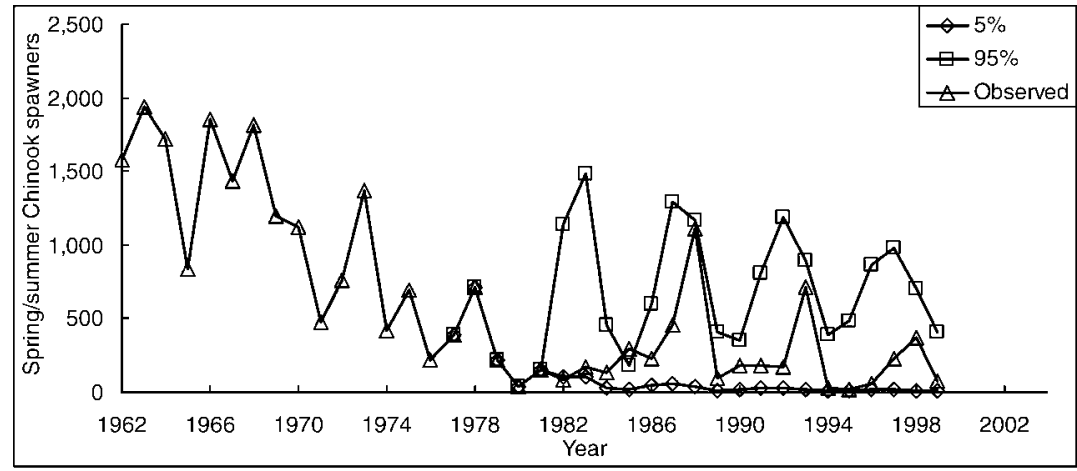

6a.-Ricker model

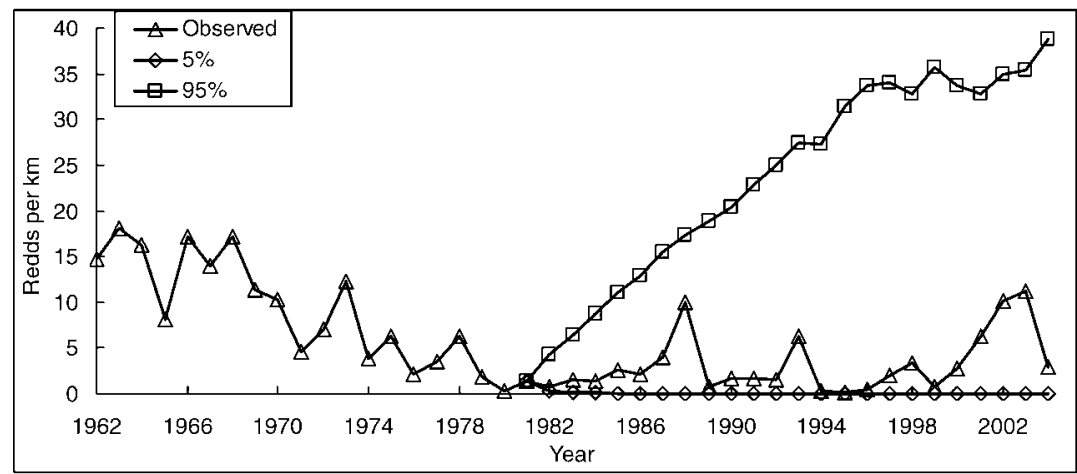

6b.-Dennis model

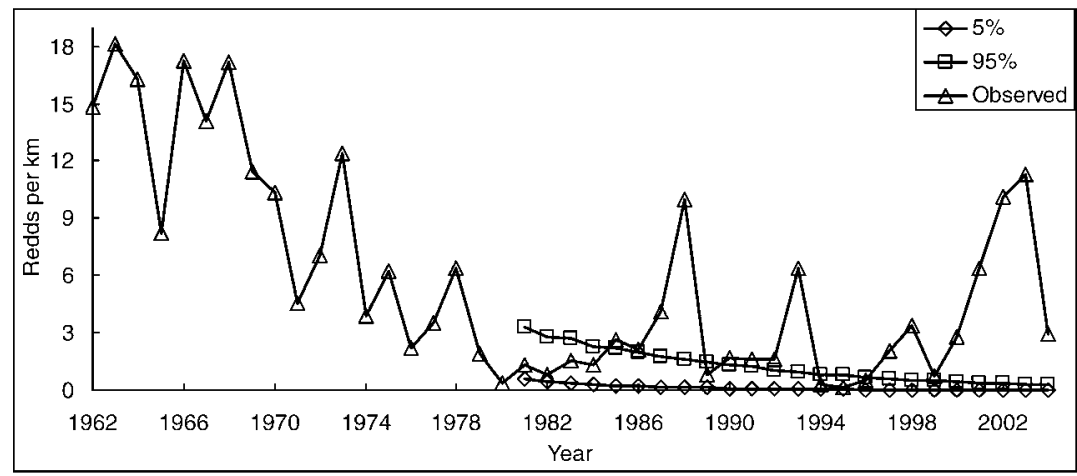

$6 \mathrm{c}$ - State-space model

Figure 6.-Model results for the Bear Valley-Elk Creek index stock. Panel (a) shows the number of wild spring-summer-run Chinook salmon spawners as estimated by the Ricker model; panels (b) and (c) show the number of redds per kilometer as estimated by the Dennis and state-space models, respectively. The lines represent the observed values and the 5th and 95th percentiles of the model estimates. 


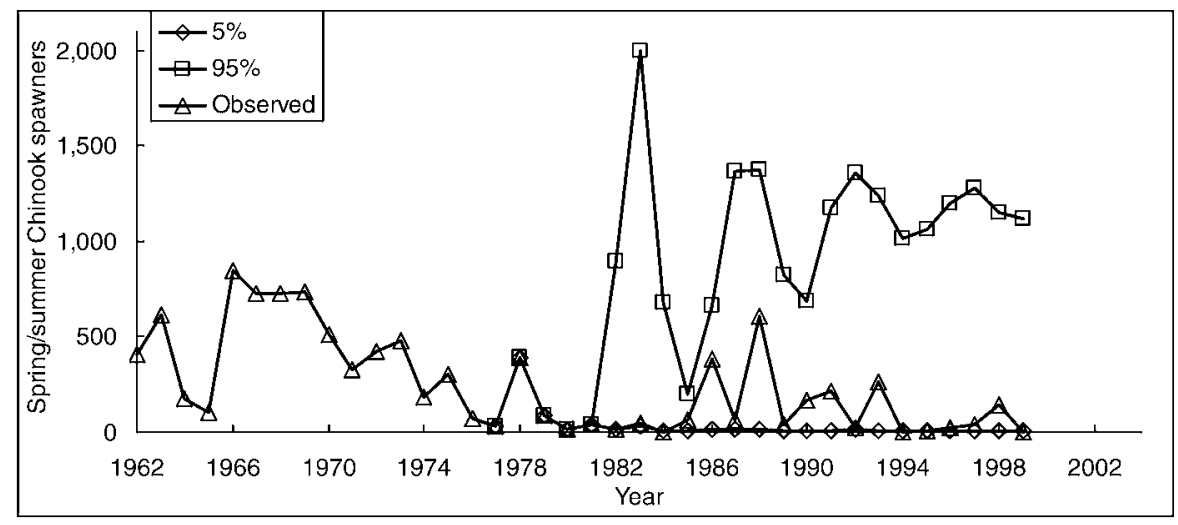

7a.-Ricker model

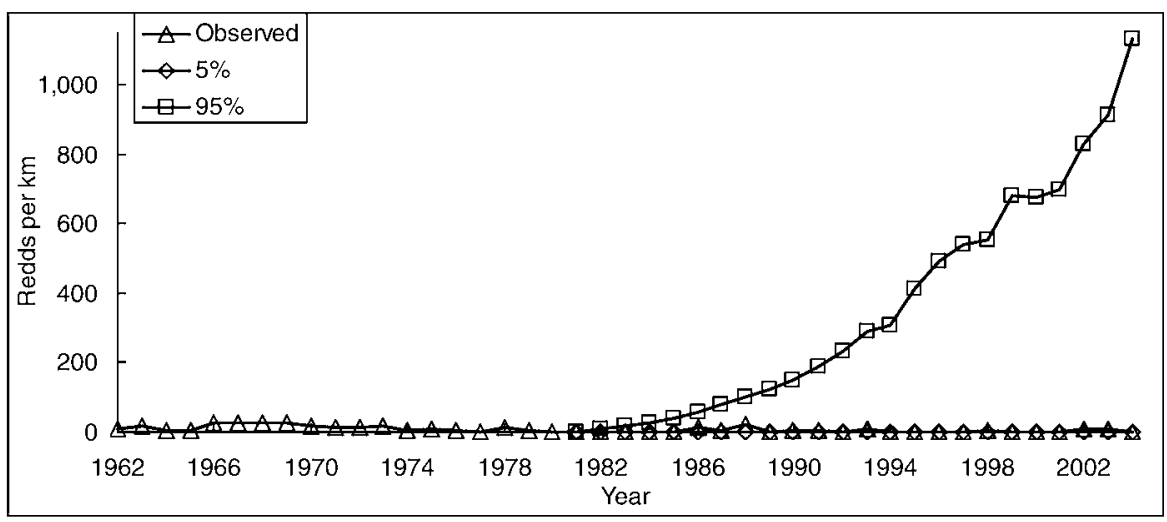

7b.-Dennis model

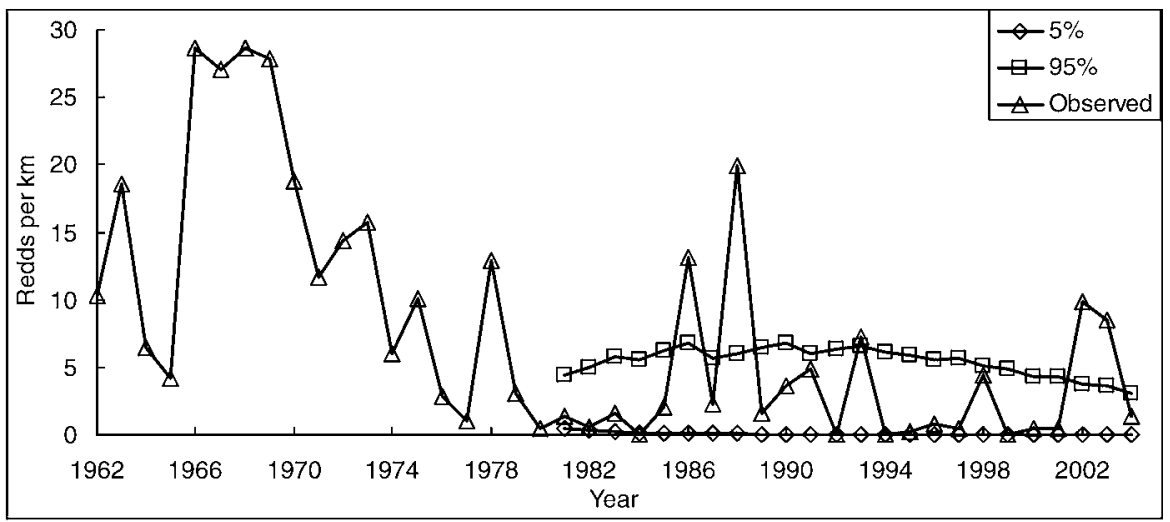

7c.- State-space model

FIGURE 7.-Model results for the Sulfur Creek index stock (see Figure 6 for additional details). 
(NOAA BRT 2003). Predictions using dam count data were not systematically tighter than those using redds or recruits per spawner despite the fact that dam counts have fewer potential sources of measurement error. These problems can also occur with healthy stocks: application of the Dennis and state-space models to spring Chinook salmon in the John Day basin, Oregon, resulted in very broad projections for the Dennis model and misattribution of variance to measurement error for the state space model.

What can be done to address these problems? First, we do not believe that state-space estimation techniques (or any other techniques known to us) applied to PVA are very useful for determining the extent of measurement error in time series of Pacific salmon abundance. If one needs to know precisely how many fish return to spawn (for example, as a means of detecting the effects of management actions on survival rates), then one must make more precise and accurate measurements rather than concocting more sophisticated (and more complicated) models. The trade-off, of course, is that more accurate methods (e.g., enumeration of adult spawners at weirs, repeated redd counts of entire spawning areas, using mark-recapture techniques) are more costly than less accurate methods, such as walking or flying an index area once to count redds.

Second, we strongly suspect that the high variability in the abundance of Pacific salmon populations will almost always preclude making accurate long-term predictions of abundance. We can think of only one exception. If one can both establish a strong correlation between abundance and some other factors (e.g., ocean conditions; Zabel et al. 2006) and accurately predict the values of those factors into the future, then it may be possible to make accurate long-term predictions. However, predicting changes in climate or other environmental covariates over several decades is, at best, very difficult. While harvest and other anthropogenic factors (e.g., dams, tributary habitat degradation) are obvious problems for the stocks analyzed here and for many other Pacific salmon stocks, changes in anthropogenic factors are unlikely to be the sole cause of either the general decline of ESA-listed stocks through the mid-1990s or the recent (post-2000) increases in adult spawner abundance. Application of much more complex models (e.g., Marmorek and Peters 1998), which explicitly incorporate harvest, hydrosystem, climate, and other effects, have very broad bounds on their population projections. Adding model complexity seems unlikely to reduce uncertainty in projections of abundance.

Rather than trying to predict future spawner abundance, it may be more useful to emphasize the development of data and analytical methods to assess the effects of human actions (beneficial or otherwise) on salmon life stage survival and productivity. Recent analyses on this topic for these stocks have demonstrated that this is possible (e.g., Paulsen and Fisher 2005; Williams et al. 2005). Given that most human actionswith the significant exception of marine harvest-occur in freshwater environments, their effects are at least potentially monitorable using well-established technologies. These include use of passive integrated transponder (PIT) tags to estimate survival rates, operating juvenile migrant traps to estimate changes in juvenile production, and weirs to make accurate estimates of spawner abundance. This approach is preferable to making untenable predictions about the future trajectories of highly variable salmon stocks.

\section{Acknowledgments}

The work was supported by contracts with the Bonneville Power Administration. The views are those of the authors. We thank the biologists from IDFG, ODFW, and the Nez Perce and Shoshone-Bannock Tribal Fisheries departments who conducted the redd counts.

\section{References}

Beamesderfer, R. C. P., H. A. Schaller, M. P. Zimmerman, C. E. Petrosky, O. Langness, and L. LaVoy. 1996. Spawner-recruit data for spring and summer Chinook salmon populations in Idaho, Oregon, and Washington. Bonneville Power Administration, Portland, Oregon.

Boggs, C. T., M. L. Keefer, C. A. Peery, T. C. Bjornn, and L. C. Stuehrenburg. 2004. Fallback, reascension, and adjusted fishway escapement estimates for adult Chinook salmon and steelhead at Columbia and Snake river dams. Transactions of the American Fisheries Society 133:932949.

Byrd, R. H., P. Lu, J. Nocedal, and C. Zhu. 1995. A limitedmemory algorithm for bound constrained optimization. SIAM Journal on Scientific Computing 16:1190-1208.

Columbia River DART (Data Access in Real-Time). 2005. DART adult passage data glossary. School of Aquatic and Fishery Sciences, University of Washington, Seattle. Available: http://www.cbr.washington.edu/dart/help/ adult_def.html. (October 2005.)

Dennis, B., P. L. Munholland, and J. M. Scott. 1991. Estimation of growth and extinction parameters for endangered species. Ecological Monographs 61:115143.

Dunham, A. E., H. R. Akcakaya, and B. S. Todd. 2006. Using scalar models for precautionary assessments of threatened species. Conservation Biology 20(5):1499-1506.

Ellner, S. P., and J. Fieberg. 2003. Using PVA for management despite uncertainty: effects of habitat, hatcheries, and harvest on salmon. Ecology 84:13591369.

Essington, T. E., T. P. Quinn, and V. E. Ewert. 2000. Intraand interspecific competition and the reproductive success of sympatric Pacific salmon. Canadian Journal of Fisheries and Aquatic Sciences 57:205-213. 
Fieberg, J., and S. P. Ellner. 2000. When is it meaningful to estimate an extinction probability? Ecology 81:2040 2047.

Hinrichsen, R. A. 2001. High variability in spawner-recruit data hampers learning. Canadian Journal of Fisheries and Aquatic Sciences 58:769-776.

Holmes, E. E., and B. X. Semmens. 2004. Viability analysis for endangered metapopulations: a diffusion approximation approach. Pages 565-597 in I. Hanski and O. E. Gaggiotti, editors. Ecology, genetics, and evolution of metapopulations. Academic Press, San Diego, California.

Holmes, E. E. 2001. Estimating risks in declining populations with poor data. Proceedings of the National Academy of Sciences of the USA 98:5072-5077.

Holmes, E. E. 2004. Beyond theory to application and evaluation: diffusion approximations for population viability analysis. Ecological Applications 14:12721293.

IDFG (Idaho Department of Fish and Game). 2005. Unpublished redd count records in Idaho Fish and Wildlife Information System (IFWIS). IDFG, Boise.

iGage Mapping Corp. 2005. All topo maps. iGage Mapping Corp. Salt Lake City, Utah. Available: http://www.igage. com. (October 2005.)

Kiefer, R. B., J. Johnson, P. R. Bunn, and A. Bolton. 2004. Natural Production Monitoring and Evaluation Project progress: 2002 annual report. Idaho Department of Fish and Game, Boise. Available: https://research.idfg.idaho. gov/Fisheries \%20Research\%20Reports/Forms/ Show\%20by\%20Author.aspx (October 2005.)

Ludwig, D. 1999. Is it meaningful to estimate a probability of extinction? Ecology 80:298-310.

Lutch, J., C. Beasley, and K. Steinhorst. 2003. Evaluation and statistical review of Idaho supplementation studies. Bonneville Power Administration, Project 1989-09800, Report DOE/BP-00006630-2, Portland, Oregon. Available: https://research.idfg.idaho.gov/Fisheries\% 20Research\%20Reports/Forms/Show\%20by\%20Author. aspx. (October 2005.)

Marmorek, D. R., and C. N. Peters, editors. 1998. Plan for Analyzing and Testing Hypotheses (PATH): Retrospective and prospective analyses of spring/summer-run Chinook. Report by ESSA Technologies, Ltd., to the Bonneville Power Administration, Portland, Oregon.

Matthews, G. M., and R. S. Waples. 1991. Status review for Snake River spring and summer Chinook salmon. NOAA Technical Memorandum NMFS F/NWC-200. Available: http://www.nwfsc.noaa.gov/publications/techmemos/ tm200/tm200.htm. (October 2005.)

Morris, W. F., P. L. Bloch, B. R. Hudgens, L. C. Moyle, and J. R. Stinchcombe. 2002. Population viability analysis in endangered species recovery plans: past use and future improvements. Ecological Applications 12:708-712.

NOAA BRT (National Oceanic and Atmospheric Administration, Biological Review Team). 2003. Preliminary conclusions regarding the updated status of listed ESUs of West Coast salmon and steelhead. Available: http:// www.nwr.noaa.gov/BRTdraftreport/BRTdraftreport. html. (October 2005.)

NOAA (National Oceanic and Atmospheric Administration) Fisheries. 2005. Endangered Species Act status of West
Coast salmon \& steelhead. Available: http://www.nwr. noaa.gov/1salmon/salmesa/index.htm. (October 2005.)

ODFW (Oregon Department of Fish and Wildlife). 2004. 1962-2003 redd count reports. ODFW, LaGrande.

Paulsen, C. M., and T. R. Fisher. 2005. Do habitat actions affect juvenile survival? An information-theoretic approach applied to endangered Snake River Chinook salmon. Transactions of the American Fisheries Society 134:68-85.

Paulsen, C. M., and R. A. Hinrichsen. 2002. Experimental management for Snake River spring/summer-run Chinook (Oncorhynchus tshawytscha): trade-offs between conservation and learning for a threatened species. Canadian Journal of Fisheries and Aquatic Sciences 59:717-725.

Petrosky, C. E., H. A. Schaller, and P. Budy. 2001. Productivity and survival rate trends in the freshwater spawning and rearing stage of Snake River Chinook salmon (Oncorhynchus tshawytscha). Canadian Journal of Fisheries and Aquatic Sciences 58:1196-1207.

Ricker, W. E. 1954. Stock and recruitment. Journal of the Fisheries Research Board of Canada 11:559-623.

Schaller, H. A., C. E. Petrosky, and O. P. Langness. 1999. Contrasting patterns of productivity and survival rates for stream-type Chinook salmon (Oncorhynchus tshawytscha) populations of the Snake and Columbia rivers. Canadian Journal of Fisheries and Aquatic Sciences 56:1031-1045.

Staples, D. F., M. L. Taper, and B. Dennis. 2004. Estimating population trend and process variation for PVA in the presence of sampling error. Ecology 85:923-929.

StreamNet. 2005. PNW reach file, 1:100,000 river reach file system, version 2.4. StreamNet, Portland, Oregon. Available: http://www.streamnet.org/pnwr/pnwrhome. html. (October 2005.)

USACE (U.S. Army Corps of Engineers). 2003. 2002 annual fish passage report: Columbia and Snake rivers for salmon, steelhead, shad, and lamprey. USACE, Portland, Oregon. Available: https://www.nwp.usace.army.mil/op/ fishdata/docs/afpr2002real.pdf. (October 2005.)

USACE (U.S. Army Corps of Engineers). 2005. Adult fish counts. USACE, Portland, Oregon. Available: https:// www.nwp.usace.army.mil/op/fishdata/home.asp. (October 2005.)

Waples, R. S., R. P. Jones, B. R. Beckman, and G. A. Swan. 1991. Status review for Snake River fall Chinook salmon. NOAA Technical Memorandum NMFS F/ NWC-201. Available: http://www.nwfsc.noaa.gov/ publications/techmemos/tm201/index.html. (October 2005.)

Williams, J. G., S. G. Smith, R. W. Zabel, W. D. Muir, M. D. Scheuerell, B. P. Sandford, D. M. Marsh, R. A. McNatt, and S. Achord. 2005. Effects of the federal Columbia River power system on salmonid populations. NOAA Technical Memorandum NMFS-NWFSC-63. Available: h t t p: //www.nwf s c.noaa.gov/as sets / $25 /$ 6061_04142005_152601_effectstechmemo63final.pdf. (October 2005.)

Zabel, R. W., M. D. Scheuerell, M. M. McClure, and J. G. Williams. 2006. The interplay between climate variability and density dependence in the population viability of Chinook salmon. Conservation Biology 20(1):190-200. 


\section{Appendix 1: Chinook Salmon Data Used for Model Analyses}

TABLE A.1.-Adult spring-summer-run Chinook salmon counted at the four Snake River main-stem dams, estimated wild adults at the uppermost dam, redds per kilometer above Lower Granite dam (excluding the Clearwater basin), age-3 to age-5 returns and recruits to the uppermost dam (no count data were available for Little Goose dam from 1982 to 1990).

\begin{tabular}{|c|c|c|c|c|c|c|c|c|c|c|}
\hline \multirow[b]{2}{*}{ Year } & \multicolumn{4}{|c|}{ Total adults by dam } & \multirow{2}{*}{$\begin{array}{l}\text { Wild adults } \\
\text { at uppermost } \\
\text { dam }\end{array}$} & \multirow[b]{2}{*}{ Redds/km } & \multicolumn{3}{|c|}{ Returns } & \multirow[b]{2}{*}{$\begin{array}{c}\text { Age } 4-5 \\
\text { recruits }\end{array}$} \\
\hline & $\begin{array}{c}\text { Ice } \\
\text { Harbor }\end{array}$ & $\begin{array}{c}\text { Lower } \\
\text { Monumental }\end{array}$ & $\begin{array}{c}\text { Little } \\
\text { Goose }\end{array}$ & $\begin{array}{l}\text { Lower } \\
\text { Granite }\end{array}$ & & & Age 3 & Age 4 & Age 5 & \\
\hline 1962 & 64,252 & & & & 64,252 & 9.57 & 3,969 & 29,436 & 34,816 & 60,810 \\
\hline 1963 & 47,653 & & & & 47,653 & 8.45 & 8,704 & 17,401 & 30,252 & 49,890 \\
\hline 1964 & 44,699 & & & & 43,746 & 9.42 & 4,246 & 26,427 & 17,319 & 52,697 \\
\hline 1965 & 21,894 & & & & 21,089 & 5.56 & 4,320 & 12,044 & 9,044 & 63,682 \\
\hline 1966 & 54,518 & & & & 52,264 & 8.72 & 6,789 & 28,006 & 24,258 & 36,209 \\
\hline 1967 & 57,724 & & & & 56,143 & 8.93 & 6,543 & 23,339 & 32,804 & 48,543 \\
\hline 1968 & 63,021 & & & & 57,125 & 8.18 & 6,296 & 30,574 & 26,551 & 38,973 \\
\hline 1969 & 76,907 & 68,274 & & & 64,089 & 5.91 & 4,790 & 41,965 & 22,123 & 24,239 \\
\hline 1970 & 61,289 & 58,881 & 54,402 & & 45,734 & 6.33 & 2,836 & 24,017 & 21,717 & 23,495 \\
\hline 1971 & 52,397 & 47,800 & 43,168 & & 38,308 & 5.80 & 4,500 & 26,116 & 12,192 & 9,632 \\
\hline 1972 & 68,541 & 62,150 & 57,102 & & 38,073 & 7.20 & 1,519 & 15,646 & 22,427 & 18,743 \\
\hline 1973 & 70,384 & 71,326 & 63,711 & & 38,788 & 7.92 & 746 & 15,461 & 23,327 & 56,498 \\
\hline 1974 & 27,738 & 26,197 & 23,060 & & 18,344 & 3.70 & 562 & 9,566 & 8,778 & 6,790 \\
\hline 1975 & 27,344 & 27,713 & 23,676 & 23,722 & 17,776 & 3.97 & 152 & 3,847 & 13,929 & 4,290 \\
\hline 1976 & 27,719 & 25,480 & 24,065 & 22,885 & 14,483 & 2.48 & 1,230 & 8,697 & 5,785 & 8,938 \\
\hline 1977 & 51,898 & 44,990 & 45,187 & 43,913 & 29,128 & 3.48 & 899 & 19,082 & 10,046 & 11,384 \\
\hline 1978 & 59,253 & 55,344 & 54,424 & 52,362 & 40,978 & 8.28 & 15 & 3,562 & 37,416 & 14,077 \\
\hline 1979 & 10,259 & 8,825 & 9,980 & 9,467 & 5,287 & 1.49 & 401 & 2,025 & 3,228 & 5,692 \\
\hline 1980 & 10,628 & 8,101 & 8,333 & 8,148 & 5,882 & 0.76 & 442 & 3,868 & 2,265 & 7,703 \\
\hline 1981 & 18,908 & 17,295 & 16,724 & 16,441 & 10,680 & 2.00 & 606 & 6,169 & 5,070 & 11,236 \\
\hline 1982 & 18,506 & 19,089 & & 16,577 & 10,648 & 1.41 & 628 & 6,077 & 5,215 & 10,352 \\
\hline 1983 & 16,510 & 16,639 & & 13,412 & 9,400 & 1.87 & 253 & 1,965 & 8,000 & 15,568 \\
\hline 1984 & 13,624 & 14,393 & & 11,940 & 7,428 & 1.62 & 421 & 3,927 & 3,727 & 4,449 \\
\hline 1985 & 35,360 & 31,657 & & 30,145 & 7,941 & 2.27 & 298 & 5,046 & 3,776 & 5,667 \\
\hline 1986 & 45,021 & 43,570 & & 37,730 & 9,579 & 2.26 & 555 & 5,098 & 6,190 & 7,935 \\
\hline 1987 & 37,835 & 36,714 & & 34,726 & 9,738 & 3.25 & 184 & 5,715 & 5,254 & 6,278 \\
\hline 1988 & 40,778 & 39,716 & & 35,640 & 10,388 & 3.92 & 200 & 1,687 & 9,853 & 15,832 \\
\hline 1989 & 18,829 & 19,656 & & 16,124 & 5,328 & 1.17 & 371 & 2,786 & 2,762 & 3,085 \\
\hline 1990 & 26,142 & 25,342 & & 22,408 & 6,558 & 1.47 & 80 & 4,045 & 2,881 & 873 \\
\hline 1991 & 14,874 & 12,868 & 10,563 & 10,432 & 5,173 & 1.26 & 286 & 1,517 & 3,890 & 1,310 \\
\hline 1992 & 29,394 & 26,793 & 24,372 & 24,405 & 11,575 & 1.81 & 346 & 6,704 & 4,761 & 5,386 \\
\hline 1993 & 31,513 & 31,475 & 30,400 & 28,924 & 9,953 & 3.01 & 109 & 1,696 & 9,128 & 11,999 \\
\hline 1994 & 4,340 & 4,513 & 4,006 & 3,915 & 1,599 & 0.59 & 13 & 332 & 1,389 & 2,861 \\
\hline 1995 & 2,257 & 2,533 & 2,098 & 1,799 & 1,088 & 0.29 & 109 & 621 & 541 & \\
\hline 1996 & 9,250 & 9,107 & 8,379 & 6,814 & 3,274 & 0.76 & 215 & 2,784 & 689 & \\
\hline 1997 & 50,594 & 47,632 & 47,246 & 44,564 & 7,263 & 1.72 & 136 & 4,957 & 2,602 & \\
\hline 1998 & 17,907 & 14,888 & 14,810 & 14,208 & 8,002 & 1.65 & 198 & 1,295 & 7,042 & \\
\hline 1999 & 14,602 & 7,296 & 6,718 & 6,556 & 2,688 & 0.91 & 398 & 1,866 & 1,566 & \\
\hline 2000 & 43,048 & 40,200 & 38,628 & 37,755 & 7,333 & 2.12 & & & & \\
\hline 2001 & 186,443 & 200,074 & 190,752 & 185,693 & 28,951 & 4.64 & & & & \\
\hline 2002 & 111,814 & 100,048 & 98,086 & 97,184 & 37,696 & 5.49 & & & & \\
\hline 2003 & 98,912 & 89,321 & 83,357 & 87,031 & 34,699 & 5.40 & & & & \\
\hline
\end{tabular}




\section{Appendix 2: Data Sources}

Snake River Spring-Summer-Run Chinook Salmon Dam Counts

Chinook salmon are counted at the four main-stem Snake River dams as they ascend the river to spawn (USACE 2005). The fish are counted by trained observers at viewing windows in the fish ladders daily from April 1 to October 31 (0400-2000 hours) and recorded on video from April 1 to December 15 (0000 2400 hours; counting methods, dates, and times varied until 2002; USACE 2003). Chinook salmon are assigned to a run (spring, summer, or fall) based on dates that vary by dam (e.g., at Lower Granite Dam, spring $=$ March 1-June 17, summer $=$ June 18-August
17, and fall $=$ August 18-December 15). Adult Chinook salmon (ages 4-5) are identified at the dams as those fish that are greater than $560 \mathrm{~mm}$ total length (Columbia River DART 2005). The dam counts are the total numbers of adult spring and summer Chinook salmon (wild- and hatchery-origin adults combined; Table 3 A.1).

\section{Snake River Wild Spring-Summer-Run Chinook Salmon Escapement and Recruits}

The estimated escapement of wild-origin adult spring-summer-run Chinook salmon above the uppermost dam on the Snake River was obtained from three

TABLE A.2.- Snake River spring-summer-run Chinook salmon index stocks: estimated spawners, recruits, and redds per kilometer.

\begin{tabular}{|c|c|c|c|c|c|c|c|c|c|c|c|c|}
\hline \multirow[b]{2}{*}{$\begin{array}{l}\text { Brood } \\
\text { year }\end{array}$} & \multicolumn{3}{|c|}{ Minam } & \multicolumn{3}{|c|}{ Imnaha } & \multicolumn{3}{|c|}{ Poverty Flat } & \multicolumn{3}{|c|}{ Johnson } \\
\hline & $\begin{array}{c}\text { Adult } \\
\text { spawners }\end{array}$ & $\begin{array}{c}\text { Total } \\
\text { recruits }\end{array}$ & $\begin{array}{l}\text { Redds } \\
\text { per km }\end{array}$ & $\begin{array}{c}\text { Adult } \\
\text { spawners }\end{array}$ & $\begin{array}{c}\text { Total } \\
\text { recruits }\end{array}$ & $\begin{array}{l}\text { Redds } \\
\text { per km }\end{array}$ & $\begin{array}{c}\text { Adult } \\
\text { spawners }\end{array}$ & $\begin{array}{c}\text { Total } \\
\text { recruits }\end{array}$ & $\begin{array}{l}\text { Redds } \\
\text { per km }\end{array}$ & $\begin{array}{c}\text { Adult } \\
\text { spawners }\end{array}$ & $\begin{array}{c}\text { Total } \\
\text { recruits }\end{array}$ & $\begin{array}{l}\text { Redds } \\
\text { per km }\end{array}$ \\
\hline 1962 & 902 & 572 & 9.0 & 1,136 & 759 & 15.1 & 2,291 & 1,756 & 41.6 & 562 & 635 & 63.0 \\
\hline 1963 & 512 & 350 & 4.8 & 528 & 1,489 & 8.1 & 1,546 & 1,040 & 33.3 & 466 & 436 & 56.8 \\
\hline 1964 & 652 & 439 & 7.7 & 1,147 & 1,035 & 15.2 & 1,385 & 893 & 24.6 & 664 & 422 & 66.2 \\
\hline 1965 & 601 & 660 & 6.7 & 863 & 1,335 & 11.5 & 511 & 1,473 & 16.1 & 134 & 619 & 24.8 \\
\hline 1966 & 550 & 581 & 6.4 & 939 & 937 & 13.6 & 1,279 & 775 & 23.3 & 202 & 380 & 23.5 \\
\hline 1967 & 212 & 624 & 2.5 & 1,007 & 2,274 & 13.1 & 1,017 & 747 & 20.8 & 637 & 565 & 61.1 \\
\hline 1968 & 410 & 496 & 5.1 & 1,149 & 2,446 & 14.7 & 401 & 1,075 & 11.8 & 235 & 789 & 27.1 \\
\hline 1969 & 627 & 505 & 8.2 & 1,399 & 1,333 & 18.4 & 904 & 477 & 15.9 & 593 & 325 & 58.3 \\
\hline 1970 & 616 & 488 & 8.1 & 849 & 1,169 & 10.7 & 774 & 356 & 13.7 & 253 & 308 & 27.8 \\
\hline 1971 & 406 & 169 & 5.3 & 1,588 & 423 & 22.3 & 469 & 276 & 8.1 & 411 & 166 & 39.1 \\
\hline 1972 & 611 & 294 & 6.9 & 1,600 & 536 & 20.5 & 717 & 143 & 11.8 & 533 & 74 & 47.0 \\
\hline 1973 & 461 & 698 & 5.6 & 2,507 & 2,373 & 31.7 & 884 & 645 & 14.0 & 652 & 434 & 57.9 \\
\hline 1974 & 380 & 179 & 3.2 & 1,335 & 211 & 16.9 & 224 & 101 & 3.5 & 261 & 80 & 22.8 \\
\hline 1975 & 299 & 41 & 2.8 & 718 & 208 & 9.1 & 284 & 55 & 4.6 & 173 & 23 & 14.7 \\
\hline 1976 & 281 & 48 & 2.2 & 612 & 335 & 7.7 & 184 & 254 & 5.0 & 161 & 123 & 14.5 \\
\hline 1977 & 165 & 71 & 1.0 & 689 & 532 & 8.7 & 290 & 234 & 4.4 & 198 & 112 & 17.3 \\
\hline 1978 & 730 & 164 & 5.8 & 2,001 & 530 & 25.3 & 293 & 386 & 4.3 & 284 & 175 & 24.1 \\
\hline 1979 & 40 & 50 & 0.6 & 238 & 558 & 3.2 & 76 & 162 & 1.5 & 66 & 39 & 7.7 \\
\hline 1980 & 43 & 220 & 0.4 & 183 & 520 & 2.4 & 163 & 324 & 2.7 & 55 & 136 & 5.1 \\
\hline 1981 & 50 & 538 & 0.6 & 453 & 615 & 6.0 & 187 & 367 & 3.0 & 102 & 158 & 9.6 \\
\hline 1982 & 104 & 195 & 0.9 & 590 & 476 & 7.9 & 192 & 264 & 2.8 & 93 & 136 & 7.9 \\
\hline 1983 & 103 & 492 & 0.9 & 435 & 593 & 5.8 & 337 & 1,118 & 5.0 & 152 & 391 & 13.5 \\
\hline 1984 & 101 & 160 & 1.0 & 557 & 141 & 7.2 & 220 & 229 & 3.8 & 36 & 113 & 3.6 \\
\hline 1985 & 625 & 189 & 4.9 & 699 & 111 & 8.8 & 341 & 262 & 5.6 & 178 & 94 & 16.0 \\
\hline 1986 & 357 & 179 & 2.9 & 479 & 122 & 3.6 & 233 & 744 & 4.0 & 129 & 208 & 11.3 \\
\hline 1987 & 569 & 58 & 4.8 & 448 & 52 & 3.1 & 554 & 430 & 8.4 & 175 & 106 & 15.4 \\
\hline 1988 & 493 & 116 & 4.4 & 606 & 351 & 4.0 & 844 & 943 & 12.5 & 332 & 442 & 29.3 \\
\hline 1989 & 197 & 54 & 1.7 & 203 & 118 & 1.3 & 261 & 285 & 4.2 & 103 & 90 & 9.0 \\
\hline 1990 & 331 & 18 & 3.1 & 173 & 49 & 1.6 & 572 & 69 & 8.4 & 141 & 17 & 12.0 \\
\hline 1991 & 189 & 21 & 2.3 & 251 & 39 & 2.0 & 538 & 92 & 8.5 & 151 & 29 & 13.7 \\
\hline 1992 & 102 & 229 & 3.7 & 363 & 191 & 3.9 & 578 & 201 & 8.5 & 180 & 140 & 16.2 \\
\hline 1993 & 267 & 208 & 3.7 & 1,178 & 151 & 8.8 & 866 & 456 & 12.8 & 357 & 253 & 30.3 \\
\hline 1994 & 22 & 72 & 1.0 & 115 & 54 & 2.0 & 209 & 97 & 3.1 & 50 & 31 & 4.3 \\
\hline 1995 & 97 & & 1.1 & 81 & & 1.3 & 81 & & 1.3 & 20 & & 1.9 \\
\hline 1996 & 219 & & 2.7 & 135 & & 2.4 & 135 & & 2.4 & 49 & & 4.9 \\
\hline 1997 & 474 & & 4.7 & 363 & & 5.3 & 363 & & 5.3 & 236 & & 20.1 \\
\hline 1998 & 159 & & 3.0 & 396 & & 6.0 & 396 & & 6.0 & 119 & & 10.2 \\
\hline 1999 & 282 & & 3.6 & 153 & & 2.6 & 153 & & 2.6 & 49 & & 4.9 \\
\hline 2000 & & & 4.9 & & & 5.1 & & & 5.1 & & & 5.3 \\
\hline 2001 & & & 11.4 & & & 12.6 & & & 12.6 & & & 37.8 \\
\hline 2002 & & & 21.3 & & & 10.7 & & & 10.7 & & & 39.3 \\
\hline 2003 & & & 15.2 & & & 12.5 & & & 12.5 & & & 66.6 \\
\hline 2004 & & & 9.7 & & & 9.2 & & & 9.2 & & & 37.8 \\
\hline
\end{tabular}


sources. (The uppermost dam changed during the period of interest as new projects were added; it was Ice Harbor in 1961-1968, Lower Monumental in 1969, Little Goose in 1970-1974, and Lower Granite from 1975 on; see www.cbr.washington.edu/crisp/hydro/.) Escapement for the years 1962-1978 was obtained from Petrosky et al. (2001; Table 1, column entitled "Upper Dam Wild") Escapement for the years 19792001 was obtained from S. Kiefer, Idaho Department of Fish and Game (IDFG), Boise. Petrosky et al. (2001) used dam counts to derive wild spring-summer-run Chinook salmon spawner estimates for the years 19621999. Estimated escapement for the years 2002-2003 was obtained from S. Kiefer. The wild component was estimated by subtracting the tributary harvest of hatchery fish and the total run size from the combined wild and hatchery dam count before 2000 (see Petrosky et al. 2001) and estimated from analysis of fin-ray growth patterns from fish sampled at Lower Granite Dam thereafter (see Kiefer et al. 2004 for the general methods used). The methods used were identical to those used for the figure in NOAA BRT (2003). Although the methods used in NOAA BRT (2003) were not specified, we assume that they are similar to those used in Petrosky et al. (2001) since the wild adult escapement estimates are very similar in years in which data are available from both sources (1979-1999).

Age-4-5 adult recruits from wild adults at the

TABLE A.2.-Extended.

\begin{tabular}{|c|c|c|c|c|c|c|c|c|c|}
\hline \multirow[b]{2}{*}{$\begin{array}{c}\text { Brood } \\
\text { year }\end{array}$} & \multicolumn{3}{|c|}{ Bear Valley-Elk } & \multicolumn{3}{|c|}{ Marsh } & \multicolumn{3}{|c|}{ Sulphur } \\
\hline & $\begin{array}{c}\text { Adult } \\
\text { spawners }\end{array}$ & $\begin{array}{l}\text { Total } \\
\text { recruits }\end{array}$ & $\begin{array}{l}\text { Redds } \\
\text { per km }\end{array}$ & $\begin{array}{c}\text { Adult } \\
\text { spawners }\end{array}$ & $\begin{array}{l}\text { Total } \\
\text { recruits }\end{array}$ & $\begin{array}{l}\text { Redds } \\
\text { per km }\end{array}$ & $\begin{array}{c}\text { Adult } \\
\text { spawners }\end{array}$ & $\begin{array}{l}\text { Total } \\
\text { recruits }\end{array}$ & $\begin{array}{l}\text { Redds } \\
\text { per km }\end{array}$ \\
\hline 1962 & 1,574 & 1,885 & 23.8 & 604 & 1,255 & 9.7 & 409 & 869 & 10.3 \\
\hline 1963 & 1,936 & 1,337 & 29.2 & 651 & 675 & 10.6 & 611 & 594 & 18.5 \\
\hline 1964 & 1,716 & 1,568 & 26.2 & 1,259 & 691 & 20.2 & 179 & 887 & 6.5 \\
\hline 1965 & 838 & 1,527 & 13.2 & 686 & 783 & 12.4 & 101 & 780 & 4.2 \\
\hline 1966 & 1,851 & 618 & 27.7 & 724 & 561 & 11.6 & 845 & 471 & 28.6 \\
\hline 1967 & 1,439 & 682 & 22.7 & 1,099 & 558 & 18.6 & 724 & 451 & 27.0 \\
\hline 1968 & 1,820 & 1,625 & 27.7 & 830 & 1,013 & 13.3 & 725 & 587 & 28.6 \\
\hline 1969 & 1,198 & 384 & 18.5 & 390 & 329 & 8.0 & 731 & 200 & 27.8 \\
\hline 1970 & 1,123 & 781 & 16.7 & 829 & 467 & 16.3 & 508 & 347 & 18.8 \\
\hline 1971 & 476 & 257 & 7.4 & 490 & 87 & 10.1 & 331 & 88 & 11.7 \\
\hline 1972 & 761 & 155 & 11.3 & 555 & 80 & 11.2 & 425 & 28 & 14.3 \\
\hline 1973 & 1,371 & 1,001 & 20.0 & 934 & 609 & 18.6 & 477 & 418 & 15.7 \\
\hline 1974 & 420 & 216 & 6.2 & 382 & 92 & 7.5 & 181 & 94 & 6.1 \\
\hline 1975 & 698 & 52 & 10.1 & 358 & 17 & 7.2 & 305 & 15 & 10.1 \\
\hline 1976 & 217 & 77 & 3.6 & 76 & 56 & 1.7 & 75 & 25 & 2.8 \\
\hline 1977 & 385 & 145 & 5.6 & 178 & 118 & 3.5 & 30 & 38 & 1.0 \\
\hline 1978 & 711 & 174 & 10.3 & 491 & 70 & 9.7 & 394 & 47 & 12.9 \\
\hline 1979 & 215 & 112 & 3.1 & 83 & 73 & 1.7 & 90 & 8 & 3.0 \\
\hline 1980 & 42 & 260 & 0.6 & 16 & 178 & 0.3 & 12 & 44 & 0.4 \\
\hline 1981 & 151 & 248 & 2.2 & 115 & 199 & 2.3 & 43 & 300 & 1.4 \\
\hline 1982 & 83 & 413 & 1.3 & 71 & 228 & 1.4 & 17 & 150 & 0.6 \\
\hline 1983 & 171 & 1,210 & 2.5 & 60 & 484 & 1.2 & 49 & 615 & 1.6 \\
\hline 1984 & 137 & 89 & 2.1 & 100 & 60 & 2.1 & 0 & & 0.0 \\
\hline 1985 & 295 & 146 & 4.2 & 196 & 86 & 3.9 & 62 & 116 & 2.0 \\
\hline 1986 & 224 & 229 & 3.4 & 171 & 102 & 3.8 & 385 & 252 & 13.1 \\
\hline 1987 & 456 & 153 & 6.6 & 268 & 56 & 5.6 & 67 & 42 & 2.2 \\
\hline 1988 & 1,109 & 715 & 16.1 & 395 & 274 & 8.1 & 607 & 261 & 20.0 \\
\hline 1989 & 91 & 75 & 1.3 & 80 & 25 & 1.6 & 43 & 17 & 1.6 \\
\hline 1990 & 185 & 18 & 2.7 & 101 & 4 & 2.1 & 170 & 4 & 3.6 \\
\hline 1991 & 181 & 18 & 2.6 & 72 & 5 & 1.5 & 213 & 7 & 4.8 \\
\hline 1992 & 173 & 138 & 2.6 & 114 & 61 & 2.4 & 21 & 36 & 0.0 \\
\hline 1993 & 709 & 502 & 10.2 & 216 & 226 & 4.7 & 263 & 164 & 7.3 \\
\hline 1994 & 33 & 43 & 0.5 & 9 & 3 & 0.2 & 0 & 0 & 0.0 \\
\hline 1995 & 16 & & 0.1 & 0 & & 0.0 & 4 & & 0.2 \\
\hline 1996 & 56 & & 0.5 & 18 & & 0.4 & 23 & & 0.8 \\
\hline 1997 & 225 & & 2.0 & 110 & & 2.3 & 43 & & 0.4 \\
\hline 1998 & 372 & & 3.4 & 164 & & 3.4 & 140 & & 4.4 \\
\hline 1999 & 72 & & 0.7 & 0 & & 0.0 & 0 & & 0.0 \\
\hline 2000 & & & 2.8 & & & 1.3 & & & 0.4 \\
\hline 2001 & & & 6.4 & & & 7.3 & & & 0.4 \\
\hline 2002 & & & 10.1 & & & 7.0 & & & 9.9 \\
\hline 2003 & & & 11.3 & & & 12.6 & & & 8.5 \\
\hline 2004 & & & 2.9 & & & 1.0 & & & 1.4 \\
\hline
\end{tabular}


uppermost dam were calculated from Petrosky et al. 2001; Table 4. A.1). The seven Snake River springsummer-run Chinook salmon index stocks used in this analysis are thought to have the most complete and accurate counts and to have minimal spawning by straying hatchery fish (Beamesderfer et al. 1997). Typically, the counts have been done in index areas, a subset of the entire spawning reach used by springsummer-run Chinook salmon, and the index area counts are expanded to the entire spawning area based on the proportion of each spawning reach sampled (Schaller et al. 1999). They are expanded further from redds to spawners based on estimates of sex ratios and of prespawning mortality derived from recoveries of female carcasses with substantial numbers of unspawned eggs. This yields estimates of the total spawning population for each index stream and year. Ages of the spawners are based on body size and scale sample analysis on carcasses recovered during the surveys. After each group of recruits is assigned to its appropriate parent group (e.g., age-5 recruits in year $t$ are the progeny of brood year $t-5$ ), summing over age-classes for each brood yields the total recruits for a brood year.

\section{Snake River Basin Redds per Kilometer}

Redd counts of spring-summer-run Chinook salmon spawning above Lower Granite Dam were obtained from Oregon Department of Fish and Wildlife (ODFW) spawning survey reports from 1962 to 2003 (generally available as photocopies from the Grande Ronde Watershed District Office; ODFW 2004), tribal fisheries departments from about 1990 to 2003 (Nez Perce and Shoshone-Bannock Tribes; most contained in Lutch et al. 2003; 2003 counts and transect details for 1990-2002 from various tribal reports), and IDFG from 1962 to 2003 (IDFG 2005). Chinook salmon redds were counted either from fixed-wing aircraft or helicopters or by surveyors on foot in established river segments (transects). Most transects are counted multiple times over the course of a spawning season, and most surveys identified the total new redds counted during each survey; however, some only identified peak redds over all the surveys in a season.

We used total or peak redds (if the total was not reported) counted from transects that were consistently counted for approximately the last 10 years of the data set (except in cases of limited visibility or restricted access, e.g. forest fires) from 1962 to 2003 . We excluded transects that were dropped from long-term monitoring before 2003 or not surveyed for more than about three consecutive years. If multiple surveys were available for a transect (i.e., IDFG and the tribal fisheries departments count many streams independently, and some streams are counted both by air and on foot), we used the more consistently conducted survey (i.e., that with the more consistent starting and ending points and counting in most or all years). The length of streams surveyed $(\mathrm{km})$ was obtained from multiple sources, depending on the starting and ending points. If the survey started at a stream mouth that appears on the 1:100,000-scale U.S. Geological Survey (USGS) topographic maps, we used the river kilometers from the Pacific Northwest River Reach File database (StreamNet 2005). If the starting or ending points were described in some other way, we used stream length measured from 1:24,000 scale USGS topographic maps in electronic format (iGage Mapping Corp. 2005).

\section{Appendix 3: Restricted Maximum Likelihood Model Code}

(Available online at DOI:10.1577/T05-300.1.s1)

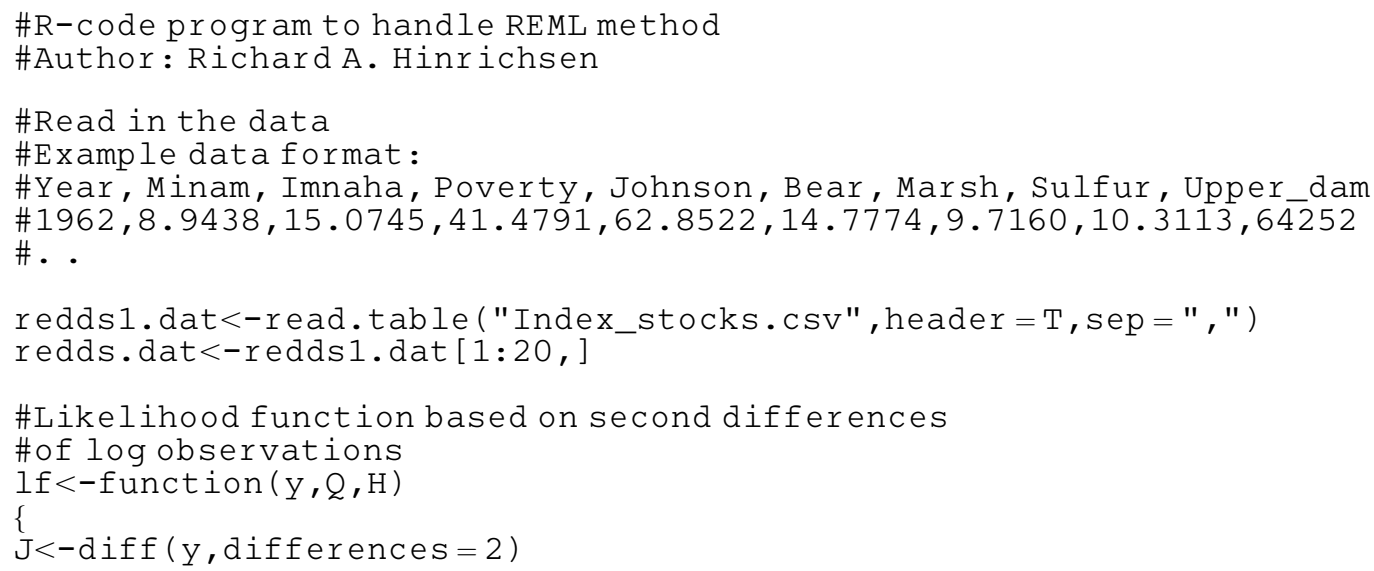




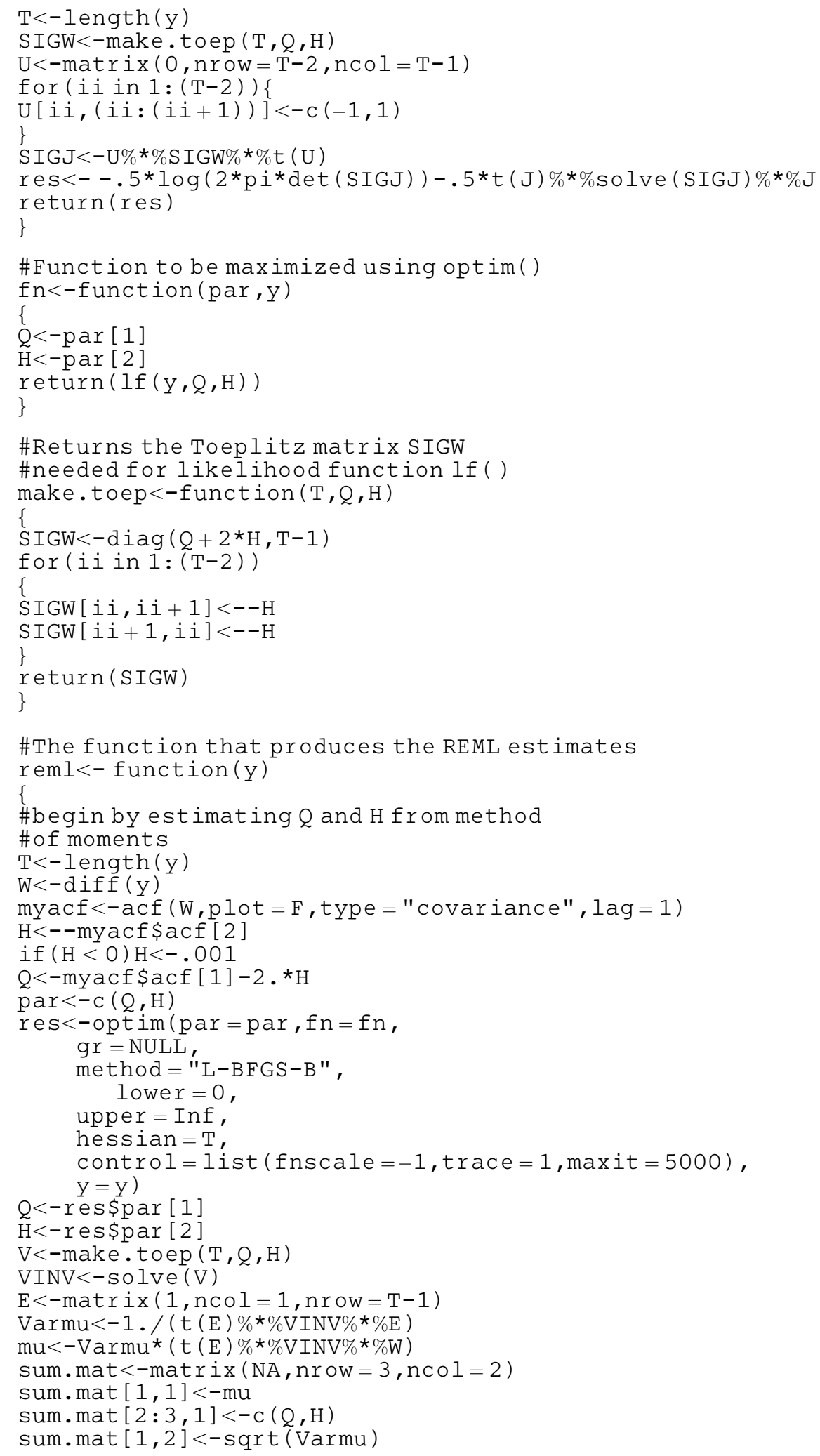




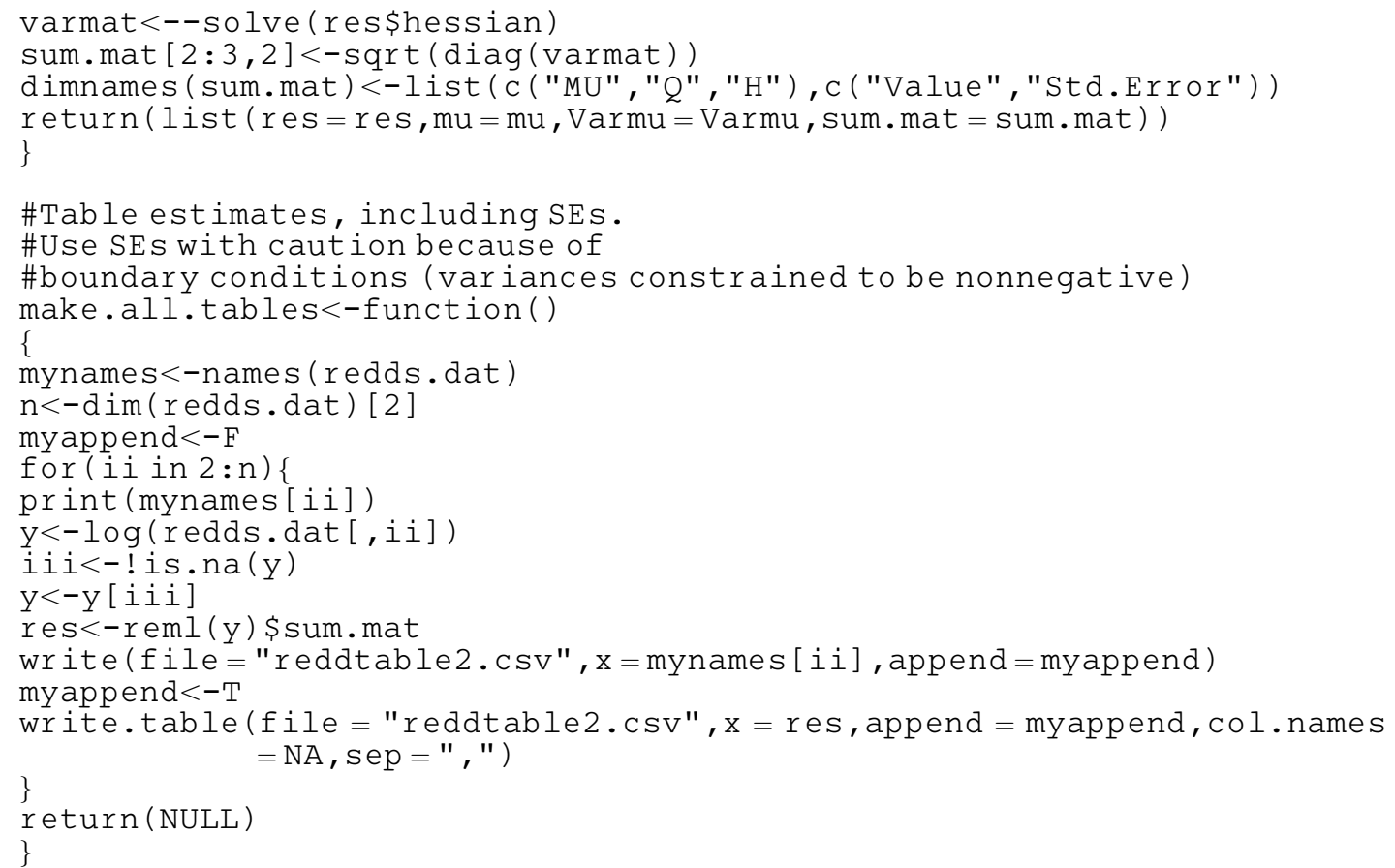

